\title{
An Empirical Analysis of the Price Discovery Function of Shanghai Fuel Oil Futures Market
}

\author{
Wang Zhen ${ }^{1}$, Liu Zhenhai ${ }^{1}$ and Chen Chao $^{2}$ \\ (1. China University of Petroleum, Beijing 102249, China) \\ (2. California State University, Northridge, CA, U.S.A)
}

\begin{abstract}
This paper analyzes the role of price discovery of Shanghai fuel oil futures market by using methods, such as unit root test, co-integration test, error correction model, Granger causality test, impulse-response function and variance decomposition. The results showed that there exists a strong relationship between the spot price of Huangpu fuel oil spot market and the futures price of Shanghai fuel oil futures market. In addition, the Shanghai fuel oil futures market exhibits a highly effective price discovery function.
\end{abstract}

Key words: Price discovery, fuel oil futures, causality, Shanghai Futures Exchange

\section{Introduction}

Influenced by the high volatility of crude oil price, fuel oil prices are also very volatile. The futures contract of fuel oil has been traded in the Shanghai Futures Exchange (SHFE) since Aug.25, 2004. It is known that the price discovery function* is one of the most important functions of futures market. Most researchers investigated the operating efficiency of international futures markets from the perspective of price discovery function (Chen and Wang, 2005). Serletis and Banack (1990) investigated the price discovery function of futures markets by using daily data of heating oil, unleaded gasoline and crude oil by the co-integration econometric method. Their conclusions supported the efficiency of futures markets. Gulen (1998) tested the crude oil futures efficiency of Nymex by using crude oil futures prices of one month, three months and six months, and found that the futures price was an unbiased estimation of spot price and indicated the price discovery function of the futures price of Nymex. This paper attempts to investigate whether the price discovery function of the Shanghai fuel oil futures market does well and plays an important role in the pricing of spot price since its opening.

Huangpu fuel oil spot price and Shanghai fuel oil futures price were studied from August 25, 2004 to June 30,2006 . A time-series econometric model was used to examine the price discovery function of Shanghai fuel oil futures market. The empirical findings showed a strong relationship between futures markets and spot markets through the co-integration test and Granger causality test and the impact of fuel oil futures price on fuel oil spot price.

\section{Data and sample}

The Huangpu (Guangdong province) fuel oil spot market is a well developed spot market in China, so Huangpu fuel oil 180cst spot price (HP) was used as the representative of spot price in China, and noted as $X_{\mathrm{HP}}$. Meanwhile, the weighted average price of Shanghai daily closing fuel oil futures price (SHFP) was considered as the representative of fuel oil futures price, and noted as $X_{\text {SHFP. }}$ In this way, we could avoid the price distortion caused by the significant volatility of certain futures prices.

For the data source, Huangpu fuel oil $180 \mathrm{cst}$ spot prices (Huangpu prices for short) were obtained from the Reuters' Platt's prices, and Shanghai fuel oil futures prices (Shanghai prices hereafter) were obtained from the public information provider Reuters (with code of SFUc2). Our sampling period was from August 25, 2004 to June 30, 2006 with 446 observation values in total.

\section{Empirical analysis}

\subsection{Analysis of correlation between Huangpu price and Shanghai price}

The scatter plots in Fig. 1 show that HP and SHFP have a positive correlation. Further estimation showed that the correlation coefficient of HP and SHFP was 0.98. However, correlation was just a statistical relationship. Further study was necessary to determine the causality between them.

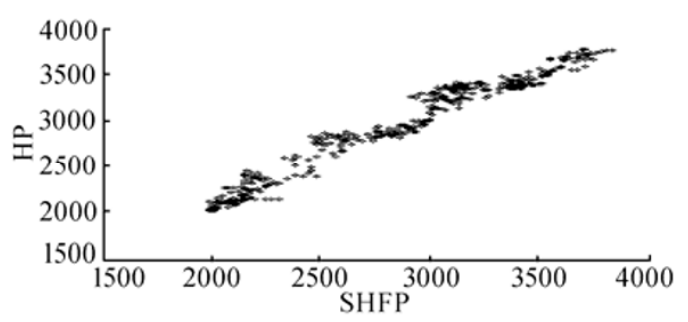

Fig. 1 Relationship between HP and SHFP

\footnotetext{
* Price discovery function is that markets influence the merchandise's price and give the appropriate price to avoid the risk of the markets.
} 


\subsection{Co-integration test of HP and SHFP 3.2.1 Stationary test}

To avoid spurious regression, a stationary test of HP and SHFP time series, called Augmented Dickey Fuller (ADF) test, was conducted before the co-integration test. The logarithm of HP and SHFP time series was used to make the trend of data more linear, since logarithm would not change the co-integration relationship between them. The test results (see Table 1) show that at the significance level of $1 \%$, the null hypothesis was accepted, namely unit roots existed in HP and SHFP time series, and HP and SHFP were non-stationary processes. At the significance level of $5 \%$, the null hypothesis was accepted, namely unit root also existed in HP and SHFP logarithm series, and HP and SHFP were non-stationary processes. But the first-order difference series of HP and SHFP logarithm series refused the unit root null hypothesis, and the first-order difference of HP and SHFP logarithms was stationary process. Variables $\mathrm{d} \ln X_{\mathrm{HP}}$ and $\mathrm{d} \ln X_{\mathrm{SHFP}}$ were integrated first-order series, and noted as I(1).

Table 1 ADF test results of HP and SHFP logarithm series and first-order difference series of their logarithms

\begin{tabular}{ccccccc}
\hline \multirow{2}{*}{ Variable } & $\begin{array}{c}\mathrm{ADF} \\
\text { test value }\end{array}$ & $\begin{array}{c}\text { 1\% Significance } \\
\text { level }\end{array}$ & $\begin{array}{c}5 \% \text { Significance } \\
\text { level }\end{array}$ & $\begin{array}{c}10 \% \text { Significance } \\
\text { level }\end{array}$ & P-value & Conclusion \\
\hline $\ln X_{\mathrm{HP}}$ & -1.063237 & -3.4473 & -2.8683 & -2.5704 & 0.2883 & Non-stationary \\
$\operatorname{d} \ln X_{\mathrm{HP}}$ & -10.60165 & -3.4473 & -2.8683 & -2.5704 & 0.0000 & Stationary \\
$\ln X_{\mathrm{SHFP}}$ & -0.669132 & -3.4473 & -2.8683 & -2.5704 & 0.5038 & Non-stationary \\
$\mathrm{d} \ln X_{\text {SHFP }}$ & -12.02925 & -3.4473 & -2.8683 & -2.5704 & 0.0000 & Stationary \\
\hline
\end{tabular}

\subsubsection{Johansen co-integration test}

Co-integration means that although a single time series is non-stationary, linear combination of two or more time series are stationary. Economic variables that satisfy co-integration would not separate too far from each other; one pulse could make them deviate from balance positions, but they would return automatically in the long term.

Based on the Variance AutoRegression (VAR) system, Johansen's co-integration test uses Maximum Likelihood Estimation (MLE) to test the co-integration between various variables. Suppose $\beta^{\prime} Y_{t}$ and $X_{t}$ were $\mathrm{K}$-order and d-order vectors respectively and followed I(1) process, we established the following VAR model:

$$
\begin{aligned}
& H_{1}: \Delta Y_{t}=\Pi Y_{t-1}+\sum_{i=1}^{p-1} \Gamma_{i} \Delta Y_{t-i}+B X_{t}+\varepsilon_{t} \\
& H_{2}: \quad \Pi=\alpha \beta^{\prime}
\end{aligned}
$$

where, $\Pi=\sum_{i=1}^{p} A_{i}-I, \quad \Gamma_{i}=-\sum_{j=t+1}^{p} A_{j}$

If the rank $r$ was less than $k$, then existed $k \times r$ order matrix $\alpha$ and $\beta$ and matrix $\Pi=\alpha \beta^{\prime}$ and $\beta^{\prime} Y_{t}$ followed the stationary $\mathrm{I}(0)$ process. Then we could do the trace test and largest eigen value test.

The unit root test showed that $\ln X_{\mathrm{HP}}$ and $\ln X_{\mathrm{SHFP}}$ were all integrated first-order I(1) process. When testing whether $\ln X_{\mathrm{HP}}$ and $\ln X_{\mathrm{SHFP}}$ were co-integrated, we should determine the optimum lag period of the VAR model. The optimum lag periods were determined by
FPE, AIC and SIC information criteria (Zhang, 2000) (see Table 2). From Table 2, it could be seen that when the lag period was 2, the average value of FPE was minimal, and when the lag period was 1 , AIC and SIC were all minimal. Thus, the optimum lag period of VAR model here was 2, and the optimum lag period of Johansen co-integration test was 1 .

Table 2 Determination of the optimum lag period of VAR model

\begin{tabular}{cccc}
\hline Lag Period & FPE & AIC & SIC \\
\hline 0 & 0.011875 & -5.7743 & -5.7559 \\
1 & 0.000197 & $-5.7798^{*}$ & $-5.7621^{*}$ \\
2 & $0.000161^{*}$ & -5.7713 & -5.7343 \\
3 & 0.000167 & -5.7692 & -5.7229 \\
4 & 0.000169 & -5.7646 & -5.7089 \\
5 & 0.000172 & -5.7604 & -5.6954 \\
\hline
\end{tabular}

Notes: *-indicates the optimum lag order; FPE is final prediction error; AIC is Akaike Information Criterion; and SIC is Schwarz Information Criterion

Johansen's co-integration method was then used to test the co-integration of SHFP logarithm series and HP logarithm series. Taking the lag period as 1 , and assuming that the series included terms of average value and linear trend and co-integration equation only contained the intercept term (these options were obtained through tests at five different situations based on Eviews 3.1), the following results were obtained (shown in Table 3). 
Table 3 Johansen co-integration test results

(Sample: 446, observation value: 446 and lag period: 1 )

\begin{tabular}{|c|c|c|c|c|c|}
\hline Variables group & Eigenvalue & Trace statistics & $5 \%$ Significance level & $1 \%$ Significance level & $\begin{array}{l}\text { Conclusion from } \\
\text { co-integration test }\end{array}$ \\
\hline \multirow{2}{*}{$\ln X_{\mathrm{HP}}$ and $\ln X_{\mathrm{SHFP}}$} & 0.050402 & 23.36953 & 15.41 & 20.04 & None* \\
\hline & 0.001035 & 0.458884 & 3.76 & 6.65 & not more than one \\
\hline Item & \multicolumn{2}{|c|}{$\ln X_{\mathrm{SHFP}}$} & \multicolumn{2}{|c|}{$\ln X_{\mathrm{HP}}$} & $\mathrm{C}$ \\
\hline Standardized co-integration coefficient & \multicolumn{2}{|c|}{1.000000} & \multicolumn{2}{|c|}{$-1.039851(0.03832)^{* *}$} & 0.345735 \\
\hline Standardized co-integration equation & \multicolumn{5}{|c|}{$\ln X_{\mathrm{SHFP}}=-1.039851 \times \ln X_{\mathrm{HP}}+0.345735$} \\
\hline
\end{tabular}

At the significance level of 5\%, Johansen's co-integration test result refused the original hypothesis in which no co-integration equation existed while it accepted the hypothesis in which one co-integration equation existed. This showed that co-integration equation existed between $\ln X_{\mathrm{SHFP}}$ and $\ln X_{\mathrm{HP}}$ at the significance level of $5 \%$, and that there was a long-term stationary relationship between them. Coefficients of standardized $\ln X_{\mathrm{SHFP}}, \ln X_{\mathrm{HP}}$ and $\mathrm{C}$ were 1.000000 , -1.039851 and 0.345735 , respectively. SHFP and HP was long-term co-integrated, the balance equation was as follows:

$$
\ln X_{\mathrm{SHFP}}=-1.039851 \times \ln X_{\mathrm{HP}}+0.345735
$$

Data in parentheses is the asymptotic standard error.

\subsection{Granger causality test}

From the co-integration test above, co-integration existed between SHFP and HP. However, only with the knowledge of co-integration lag period being 1 , we could not determine whether there was causality relationship between them, hence further study was needed. Here we adopted the widely used Granger causality test to examine the causality relationship between them.

There are two ways of test with the Granger causality test, one is the traditional test based on the VAR model and the other is the recently developed one based on the vector error correction (VEC) model. The difference lies in their different scopes of application. The former is used for testing the causality between non co-integrated series, and the latter is usually used for testing the causality between co-integrated series.

Feldstein and Stock (1994) believed that if cointegration relationship existed between non-stationary vectors, causality should be tested by using the VEC-based model, that is, the error correction term
(ECT, noted as $E$ ) in the model could not be omitted. Otherwise, the conclusion reached might be a little warped. So we did Granger causality test with the VEC-based model with the following equation:

$$
\Delta Y_{t}=\alpha_{0}+\sum_{i=1}^{m} \alpha_{i} \Delta Y_{t-i}+\sum_{j=1}^{n} \beta_{j} \Delta X_{t-j}+\theta E_{t-1}+\varepsilon_{i}
$$

where, $E_{t-1}=\beta Y_{t-1}$

where, $Y_{t}=\left(\ln X_{\mathrm{SHFP}}, \ln X_{\mathrm{HP}}\right)$, Correction factor matrix $\theta$ and $\beta_{j}(j=1,2, \cdots, n)$ were used to stand long- and short-term causality between variables, and their significance could be tested by using $t$ statistics and $F$ statistics (which regressed to $t$ statistics when the lag period was 1). At the same time, the method based on VAR model was also used to test causality in order to robust the results.

Since the Granger causality test is very sensitive to lag order, AIC and SIC were followed to obtain the best lag order and lag period 1 was taken as the best lag period. Meanwhile, the test results at other lag periods were also examined. Table 4 shows the results of the Granger causality test.

Panel A of Table 4 shows that when testing whether $\ln X_{\mathrm{SHFP}}$ was the Granger cause of $\ln X_{\mathrm{HP}}$, the coefficients of $\operatorname{dln} X_{\mathrm{SHFP}}(-1)$ and $E(-1)$ were close to zero at the significance level of $5 \%$. For the long term, the volatility of SHFP and the volatility of HP were Granger causes for each other. SHFP led one day ahead of HP. This result was corresponding to that drawn by the traditional variance-based Granger causality test in Panel B. Moreover, the coefficient $E(-1)$ for HP was negative, indicating that in the long term, price volatility of HP could be modified and adjusted through the error correction of SHFP. Furthermore, the residual test indicated that residual series were not auto-correlated. 
Table 4 Granger causality test results based on VEC

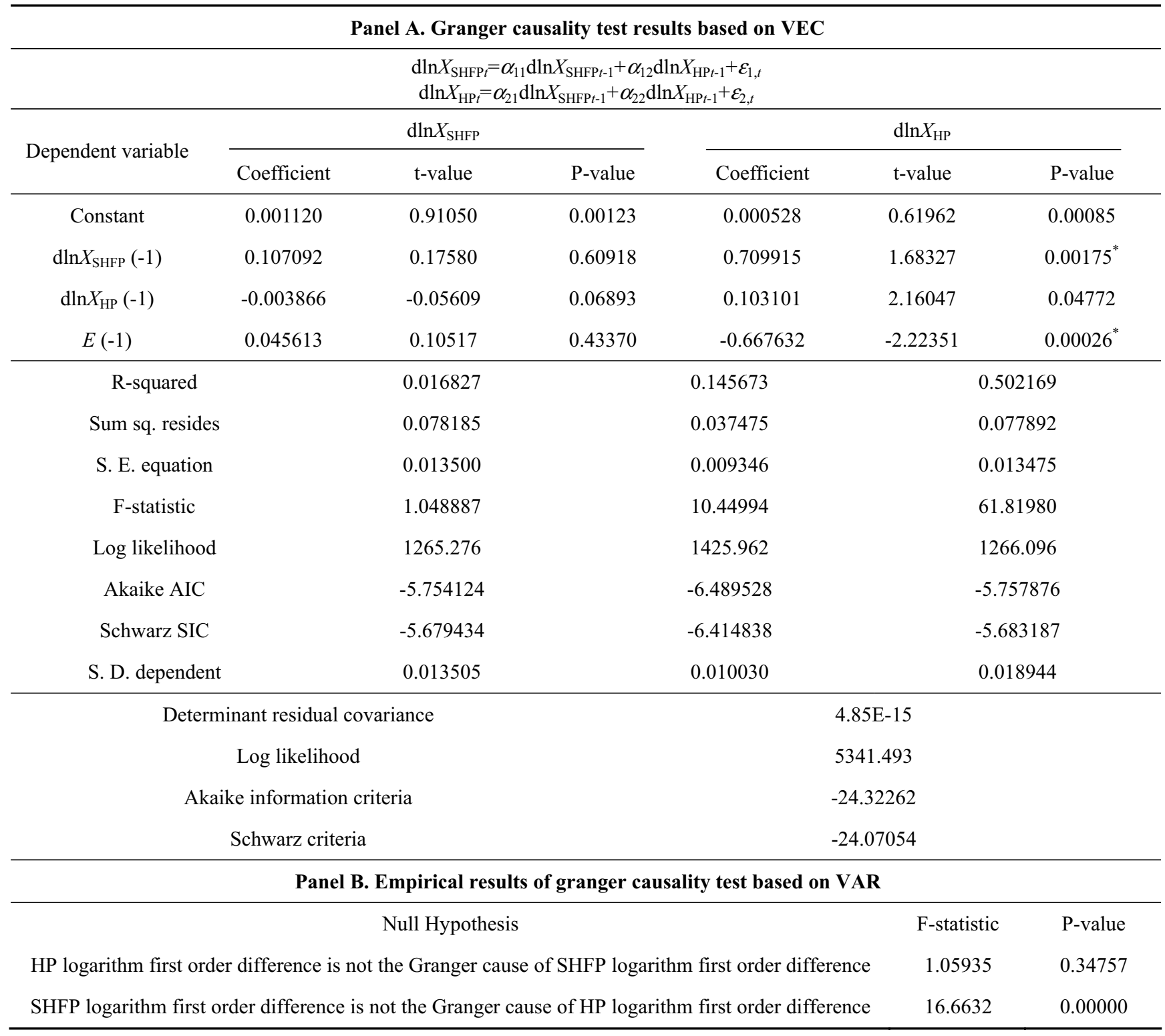

Notes: *-indicates the significance at $5 \%$ level

\subsection{Impulse response and variance decomposition}

The impulse response function (Gujarati, 2000) means the response of the system to an impulse or information of a certain variable. It is used to weigh the influence of the standard error impulse of a disturbance on the present and future value of an endogenous variable. The following VAR (1) model for two variables SHFP and HP was used:

$$
\begin{gathered}
\mathrm{d} \ln X_{\mathrm{SHFP}}=\alpha_{11} \mathrm{~d} \ln X_{\mathrm{SHFP} t-1}+\alpha_{12} \mathrm{~d} \ln X_{\mathrm{HP} t-1}+\varepsilon_{1, t} \\
\mathrm{~d} \ln X_{\mathrm{HP} t}=\alpha_{21} \mathrm{~d} \ln X_{\mathrm{SHFP} t-1}+\alpha_{22} \mathrm{~d} \ln X_{\mathrm{HP} t-1}+\varepsilon_{2, t}
\end{gathered}
$$

Disturbances in the model were called information. In the VAR (1) model made up of formulas (2) and (3), if $\varepsilon_{1, \mathrm{t}}$ changes, not only the present value of $\operatorname{dn} X_{\mathrm{SHFP}}$ will change, the future value of variables $\operatorname{d} \ln X_{\mathrm{SHFP}}$ and $\mathrm{d} \ln X_{\mathrm{HP}}$ will also be influenced. The impulse response function tries to describe the trace of the influence and to show how the disturbance of a variable influences all the remaining variables through the model and is finally reflected to itself. If the information is relevant, it will contain a common component that has no relation to any specific variable. Usually, the effect of the common component is attributed to the first appeared variable of the VAR system. Here all the common components of $\varepsilon_{1, \mathrm{t}}$ and $\varepsilon_{2, \mathrm{t}}$ were attributed to $\varepsilon_{1, \mathrm{t}}$. Thus, we examined the influence of SHFP trend on HP trend by the impulse response function to verify the price discovery function of the futures market and do assessment objectively of the running efficiency of Shanghai fuel oil futures market. 
The impulse response functions of $\operatorname{dn} X_{\text {SHFP }}$ to $\mathrm{d} \ln X_{\mathrm{HP}}$ and $\operatorname{dln} X_{\mathrm{HP}}$ to $\operatorname{dn} X_{\mathrm{SHFP}}$ were calculated by using the VAR system model of the two variables $\operatorname{dn} X_{\text {SHFP }}$ and $\mathrm{d} \ln X_{\mathrm{HP}}$. The tracing period of the impulse response was 4 days and the results of impulse test of $\operatorname{dn} X_{\text {SHFP }}$ and $\operatorname{d} \ln X_{\mathrm{HP}}$ prediction variance are shown in Table 5:

Table 5 Impulse test result of dln $X_{\text {SHFP }}$ a n d dln $X_{\mathrm{HP}}$ predicted variance

\begin{tabular}{ccc}
\hline \multicolumn{3}{c}{ Response of $\mathrm{d} \ln X_{\mathrm{SHFP}}:$} \\
\hline Period & $\mathrm{d} \ln X_{\mathrm{SHFP}}$ & $\mathrm{d} \ln X_{\mathrm{HP}}$ \\
\hline 1 & $0.013330(0.00045)$ & $0.000000(0.00000)$ \\
2 & $-0.000438(0.00063)$ & $0.000220(0.00061)$ \\
3 & $-0.001137(0.00063)$ & $-0.000857(0.00060)$ \\
4 & $0.000107(0.00021)$ & $-0.000112(9.7 \mathrm{E}-05)$ \\
\hline Period & Response of $\mathrm{d} \ln X_{\mathrm{HP}}:$ \\
\hline 1 & $0.001197(0.00045)$ & $0.009350(0.00031)$ \\
2 & $0.000310(0.00045)$ & $0.001465(0.00043)$ \\
3 & $0.002664(0.00046)$ & $0.000577(0.00043)$ \\
4 & $0.000334(0.00018) *$ & $0.000179(0.00019)$ \\
& $0 \operatorname{dln} X_{\mathrm{SHFP}}$ & \\
\hline
\end{tabular}

Notes: *-Data in parentheses is the asymptotic standard error

Fig. 2 shows the impulse response of $\operatorname{d} \ln X_{\text {SHFP }}$ and d $\ln X_{\mathrm{HP}}$ prediction variance. From Table 5 and Fig. 2, the information of standard deviation of $\operatorname{d} \ln X_{\text {SHFP }}$ to $\mathrm{d} \ln X_{\mathrm{HP}}$ responded immediately and the response was strong, but this would approach to zero in 4 days. Compared with HP, the self-impulse of SHFP had steadily declining inner strength but it became stable after one day. The direct impulse of SHFP on HP disappeared in one day automatically and vice versa. This is corresponding to the lag period mentioned above, indicating that SHFP responded more quickly than HP and that the price response of the futures market was sensitive and its price discovery function was highly efficient. To discover the contribution degree of SHFP on price discovery of the fuel oil spot market, the significance of information to endogenous variables in the model was further analyzed by using variance decomposition. The analysis results are shown in Table 6.

Table 6 shows that SHFP variance decomposition contributed more than HP variance decomposition, indicating that the SHFP exhibited a price discovery function and was highly efficient.
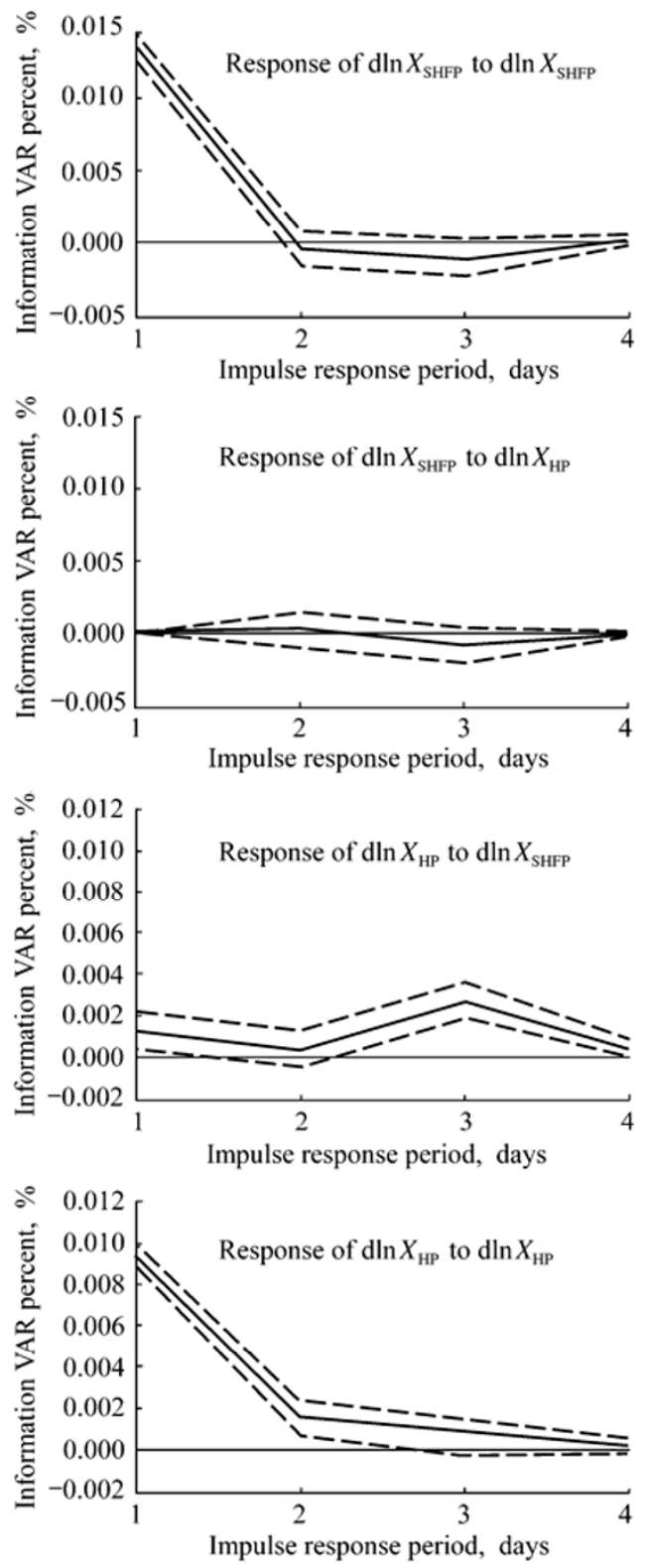

Fig. 2 Impulse Response of $d \ln X_{\text {SHFP }}$ and $\mathrm{d} \ln X_{\mathrm{HP}}$ prediction variance

Table 6 Variance decomposition of dln $X_{\mathrm{SHFP}}$ and $\mathrm{d} \ln X_{\mathrm{HP}}$

\begin{tabular}{cccc}
\hline \multirow{2}{*}{ Period } & \multicolumn{3}{c}{ Variance decomposition of $\operatorname{dln} X_{\mathrm{SHFP}}$} \\
\cline { 2 - 4 } & S.E.* & $\mathrm{d} \ln X_{\mathrm{SHFP}}$ & $\mathrm{d} \ln X_{\mathrm{HP}}$ \\
\hline 1 & 0.013330 & 100.0000 & 0.000000 \\
2 & 0.013339 & 99.97286 & 0.027144 \\
3 & 0.013414 & 99.56541 & 0.434592 \\
4 & 0.013415 & 99.55847 & 0.441525 \\
\hline \multirow{2}{*}{ Period } & \multicolumn{2}{c}{ Variance Decomposition of $\mathrm{d} \ln X_{\mathrm{HP}}$} \\
\cline { 2 - 4 } & S.E*. & $\mathrm{d} \ln X_{\mathrm{SHFP}}$ & $\mathrm{d} \ln X_{\mathrm{HP}}$ \\
\hline \multirow{4}{*}{1} & 0.009426 & 1.611911 & 98.38809 \\
2 & 0.009544 & 1.677593 & 98.32241 \\
3 & 0.009926 & 8.755767 & 91.24423 \\
4 & 0.009933 & 8.856073 & 91.14393 \\
\hline \multicolumn{4}{c}{ Ordering: $\mathrm{d} \ln X_{\mathrm{SHFP}} \mathrm{d} \ln X_{\mathrm{HP}}$} \\
\hline
\end{tabular}

Notes: *-S.E.is standard error of equations 


\section{Conclusions}

This paper investigated the influence of the price trend of Shanghai fuel oil futures market on Huangpu fuel oil spot market by using the methods, such as correlation coefficients between futures and spots price, Johansen co-integration test, error correction model, Granger causality test analysis, VAR-based impulse response function analysis and variance decomposition. The results were summarized as follows:

1) When analyzing SHFP and HP time series, it was found that the relevance between SHFP and HP was as high as 0.98 . The unit root test of these two series by using the ADF method showed that they were both non-stationary time series and became stationary I(1)series after first-order difference. All these satisfied the necessary requirements of the co-integration test.

2) The co-integration test by Johansen maximum likelihood estimation showed that SHFP and HP were co-integrated, that is, a steady equilibrium relationship existed between them in the long run and the influence of SHFP on HP was very significant.

3) The Granger causality test based on VEC showed that bi-directional Granger causes existed between SHFP and HP. And SHFP was the Granger cause of HP, that is, SHFP led the trend of HP ahead of one trading day. The error correction coefficient $E(-1)$ was negative, indicating that the price volatility of HP could be modified and adjusted through the error correction of SHFP change in the long run.

4) The empirical results of impulse response function and variance decomposition of $\operatorname{d} \ln X_{\mathrm{SHFP}}$ to $\mathrm{d} \ln X_{\mathrm{HP}}$ and $\mathrm{d} \ln X_{\mathrm{HP}}$ to $\mathrm{d} \ln X_{\mathrm{SHFP}}$ based on the VAR system model of two variables SHFP and HP showed that $\operatorname{dn} X_{\text {SHFP }}$ responded immediately to the information of a standard error of $\operatorname{dln} X_{\mathrm{HP}}$, and the response was strong, but regressed to nearly zero in 4 days. The direct impulse of SHFP to HP would disappear in one day and vice versa. This is corresponding to the lag period mentioned above.

\section{References}

Chen D. and Wang Z. (2005) A review of price discovery on international crude oil market and hedging. Journal of China University of Petroleum, 23 (3), 23-27 (in Chinese)

Feldstein and Stock (1994) Price discovery in the german equity index derivatives markets. The Journal of Futures Markets, 19, 6619-6643

Gujarati (2000) Econometrics. Beijng: China Renmin University Press

Gulen S. G. (1998) Efficiency in the crude oil futures market. Journal of Energy Finance \& Development, 3 (1), 13-21

Serletis A. and Banack D. (1990) Market Efficiency and Co-integration: An application to Petroleum Markets. The Review of Futures Markets, 9, 372-385

Zhang X. T. (2000) Econometrics Analysis. Beijing: Economic Science Press

\section{About the first Author}

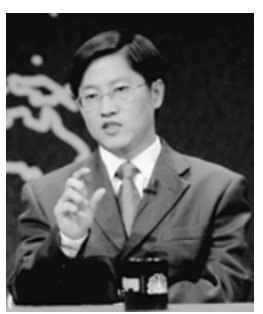

Wang Zhen was born in 1969. He received his $\mathrm{PhD}$ in finance at Peking University in 2002. Dr. Wang now works at the School of Business Administration, China University of Petroleum (Beijing) and is an associate professor in finance with his research interests in energy finance, risk management, M\&A, and international petroleum economics. E-mail: wangzhen@cup.edu.cn

(Received January 26, 2007)

(Edited by Zhu Xiuqin) 